\title{
Eventos Gastronômicos: A nova Estratégia de Marketing e divulgação utilizada pelos Restaurantes
}

\author{
André Luís Sant'Anna'; Daniele Bastos da Silva ${ }^{2}$
}

\begin{abstract}
Resumo: Os eventos de gastronomia têm assumido importante papel no cenário social na atualidade, não só por representar uma oportunidade de negócio, mas também por configurar uma forma de incentivo ao resgate de técnicas culinárias. É também uma forma de valorização da cultura regional, suas comidas, temperos e iguarias próprias de cada lugar. Essa forma de turismo, tem atraído o interesse dos consumidores, revelando-se uma importante estratégia de marketing. Este artigo discute o marketing na gastronomia e suas tendências atuais. Os resultados demonstraram que os eventos gastronômicos, têm se apresentado como método eficaz de divulgação de novos pratos e, de criação de laços entre o consumidor e a proposta dos restaurantes.
\end{abstract}

Palavras-chave: Marketing, Marketing gastronômico, Cultura regional

\section{Gastronomic Events: The New Marketing and Advertising Strategy used by Restaurants}

\begin{abstract}
Gastronomy events have assumed an important role in the social scene today, not only because it represents a business opportunity, but also because it constitutes a form of incentive to the rescue of culinary techniques. It is also a way of valuing the regional culture, its foods, spices and delicacies typical of each place. This form of tourism has attracted the interest of consumers, proving to be an important marketing strategy. This article discusses marketing in gastronomy and its current trends. The results showed that the gastronomic events have been presented as an effective method of disseminating new dishes and creating links between the consumer and the restaurants proposal.
\end{abstract}

Keywords: Marketing, Gastronomic marketing, Regional culture

\section{Introdução}

A arte da culinária está relacionada a evolução dos utensílios de cozinha, que possibilitou a modificação da forma de cozinhar, principalmente com a introdução do

\footnotetext{
${ }^{1}$ Médico pela Universidade Gama Filho - RJ. Residência em Ortopedia e Traumatologia pelo Hospital Municipal Barata Ribeiro - RJ. Pós Graduação em Biomedicina do Exercício e do Esporte pela Universidade Federal do Ceará - Fortaleza, CE. Acadêmico de Marketing pela faculdade Paraíso - FAP. Juazeiro do Norte-CE. Contato: euamoortopedia@gmail.com;

${ }^{2}$ Cirurgiã Dentista formada pela Universidade Estácio de Sá - Rio de Janeiro. Pós-Graduação em Ortodontia pela mesma universidade. Acadêmica de Gastronomia pela faculdade de Juazeiro do Norte - FJN, Ceará.
} 
cozimento de alimentos, em que foi possível também a utilização de sementes e ervas no preparo. Nesse sentido, o desenvolvimento tecnológico, tanto na agricultura quanto nas técnicas culinária em si, possibilitou o desenvolvimento da gastronomia, que se trata de área de conhecimento responsável pelo estudo dos matérias utilizados na alimentação, no ato de cozinhar e de elaboração de bebidas.

As refeições são momentos que aproximam as pessoas, criando oportunidades de estreitamento de laços, principalmente em datas festivas ou encontros entre amigos ou familiares, sendo expressão histórica, social, geográfica, climática, bem como religiosa. Com advento da gastronomia, no Brasil marcado pelo descobrimento do país, em que houve troca de costumes alimentares. Da parte dos indígenas herdou-se o hábito de se alimentar de carnes, vegetais, frutas, raízes, etc; e dos portugueses as técnicas de frituras, preparação de doces, refogados e cozidos, dando criação a uma cozinha rica, diversificada e cheia de variedades regionais.

A gastronomia está diretamente relacionada à cultura local, não sendo apenas ferramenta turísticas, mas de perpetuação dos hábitos e tradições. Sem dúvidas a cultura gastronômica movimenta o turismo, o interesse e a curiosidade das pessoas de experimentar a culinária praticadas nos diversos lugares, onde os costumes e os modos de preparo podem ser o mais inusitado possível.

Trabalhar com o setor gastronômico demanda o conhecimento de diversas áreas, tais como produção, administração e marketing. Outrossim, é um ramo que precisa as novas tendências de mercado, razão pela qual empreendedores visionários buscam criar estratégias de aproximação e manutenção de clientes. Assim, o marketing é utilizado, não só para esvaziar a necessidade alimentar do consumidor, como também para transferir significados sensoriais e emocionais, com fulcro de criar e manter a lealdade de seus clientes.

Com base nisso, o marketing analisa o perfil do mercado e do público alvo, para fins de elaborar estratégias de mercados específicas e adequadas ao caso, colaborando para A criação de mercados e desenvolvimento de relacionamentos (Britto; Fonte, 2002, p. 34). Nesse contexto, uma das formas de marketing de criar programas de comunicação e promoção das empresas, é por meio da realização de um evento gastronômico.

Os eventos de gastronomia têm assumido importante papel no cenário social da atualidade, não só por representar uma oportunidade de negócio, mas também por configurar 
uma forma de incentivo ao resgate de técnicas culinárias, bem como a valorização das comidas regionais e internacional, o que atrai o interesse dos consumidores para experimentar as diferentes culinárias, e , muitas vezes, de fidelização à estas; revelando ser uma importante estratégia de marketing.

Assim, eventos são classificados como valiosas estratégias de comunicação, que envolve relacionamento, comunicação, retenção e adaptação de categorias propostas por meio da análise do público e sua recepção ou não da culinária, produto ou técnicas apresentadas naquela oportunidade. Configurando em método eficaz de aproximação e manutenção do cliente, podendo dar ensejo ao estabelecimento de uma relação duradoura com o restaurante (GRÖNROOS, 1995; GUMMESSON, 2005; LOVELOCK, WRIGHT, 2003; MELLO, 2008).

Com base nisso, nesse estudo, pretende-se analisar a execução de eventos gastronômicos, demonstrando que consiste em estratégia de marketing eficaz para a divulgação do restaurante e possível criança de uma rede fiel de consumidores, sendo necessário, para tanto, que as partes envolvidas estejam preparadas para despertar o desejo de fidelização, bem como para manter o relacionamento com meus clientes.

\section{Marketing, público alvo e estratégia.}

Entender o conceito de marketing e para o que ele se propõe, é de suma importância para que ele seja explorado corretamente e da melhor forma por uma empresa. Conforme ensina Kotler, Armstrong e Gary (2003, p. 30), marketing trata-se das ações que são utilizadas com vistas a obter uma resposta específica de um certo público alvo quanto a um produto, serviço ou ideias.

De acordo com Pride e Ferrel (2001, p. 150) consiste em processo de criação, distribuição e promoção de bens, serviços ou ideias, que geram e facilitam a troca de informações com os clientes, gerando um meio mais dinâmico. Assim, o marketing é utilizado para criar uma estratégia de atração dos clientes de forma personalizada a depender do caso concreto. Trata-se, dessa forma, de processo desenvolvido pela empresa, com fulcro de atrair clientes por meio da satisfação de suas necessidades, agregando, dessa forma, valores ao seu público.

503 Id on Line Rev. Mult. Psic. V.12, N. 42, p. 501-514, 2018 - ISSN 1981-1179 Edição eletrônica em http://idonline.emnuvens.com.br/id 
Com o processo de globalização, inclusões sociais e constantes modificações socioeconômicas que ocorrem ao redor do mundo, fronteiras têm sido ultrapassadas, o que resultou na difusão de conhecimento acerca das inovações, produtos e padrões de qualidade, o tornando os consumidores mais exigentes. Neste cenário, formado por consumidores cada vez mais informados, a concorrência fica acirrada, pois todo dia novos produtos e serviços são inovados ou melhorados, o que exige das empresas que possuam um diferencial para se destacarem.

Além disso, a opinião e a satisfação dos consumidores são fatores importante e que influencia os demais, razão pela qual as empresas buscam agregar valores a sua marca, de forma que esta seja vista como sinônimo de satisfação. Contudo, isto não é fácil, pois os clientes não demonstram lealdade se entenderem todos os produtos como iguais. Com isso, é tarefa desafiadora, pois é preciso demonstrar ao consumidor sua diferença enquanto produto ou prestador de serviço, para que esses sintam necessidade de obter, sempre que possível, aquele produto ou marca específico (VAVRA, 1993, p. 17).

Nesse diapasão, os preceitos do marketing ensinam que a empresa deve buscar vender aquilo que o consumidor que ou precisa. Para tanto, deve observar oportunidades e problemas, para fins de desenvolver soluções inovadoras. Por meio disso, a empresa é capaz de manter seu público, já fiel, bem como atrair novos consumidores. Conforme ensina Michael R. Solomon (2002, p. 25), um dos conceitos básicos do marketing é buscar satisfazer as necessidades dos consumidores, não devendo a empresa vender o que quer, mas sim o que os clientes necessitam.

Analisar e conhecer o consumidor é função do marketing, e produz informações importantes para que a empresa seja bem direcionada. Nesse meio, analisar e entender o comportamento do consumidor é necessário para o marketing, para que ele possa ajudar a empresa a cumprir seus objetivos, bem como a colocar no mercado produtos e serviços capazes de satisfazer os desejos dos consumidores, proporcionando, assim, o sucesso do negócio (SANTOS; MOSCH, 2005, p. 2). Sendo assim, saber suas preferências, como pensam e o que os impulsionam a comprar, colabora para o correto direcionamento das estratégias de marketing, possibilitando que essas sejam corretamente direcionada para atingir o público alvo da melhor forma, agregando experiências que sejam percebidas pelo consumidor como mais valiosas do que o valor a ser dispendido. 
Sobre isso, Kotler e Keller (2005, p. 172) comentam que o comportamento e as escolhas de consumo são diretamente influenciados por fatores socioculturais, pessoais e psicológicos; e conhecer e assimila-los não se trata de tarefa fácil, isto porque demanda de uma observação meticulosa do público acerca do que os motiva a comprar, chamado de Processo de decisão do consumidor (PDC) desenvolvido por Engel, Kollat e Blackwell (2005).

Esse processo consiste em identificar as necessidades, bem como analisar o público, identificando os motivos pelos quais a pessoa compra, consume, avalia o bem no pós-consumo e porquê o descarta. É necessário olhar pelo lado do consumidor, compreendendo-o, para que as estratégias de marketing possam ser elaboradas de forma a influenciar seus comportamentos. Para uma empresa não basta apenas ter bons produtos ou uma boa imagem, a empresa deve atender e superar aquilo que o consumidor espera, seus desejos e necessidades.

Então, o marketing pode ser definido como área responsável por atividades de troca entre empresa e consumidores, orientadas a satisfazer os desejos e necessidades de seu público alvo, com base nos "4Ps", sem eles o preço, a praça, o produto e a promoção; e sempre observando o meio de atuação e o impacto que suas ações podem causar no bem-estar da social.

\section{Principais características e classificações dos eventos}

Os eventos consistem em ferramenta eficaz para agrupar pessoas de um grupo alvo específico. Vem sendo utilizados desde os primórdios da humanidade, quando, em 776 a.C., eram realizados para realizar os Jogos Olímpicos. Na Idade Média, eram utilizados principalmente com fins religiosos ou comerciais, cada um com características históricas, culturais, sociopolíticas, sociais, e econômicas particulares (MATIAS, 2010). No Brasil, foi o Baile de Carnaval, datado de 1840, o primeiro evento realizado no país em um local especialmente destinado para tanto.

Atualmente, conceitua-se evento como sendo um instrumento institucional e promocional, utilizado para criar conceito e imagem acerca de uma organização, produto, serviço, ideia ou pessoa; por meio do planejamento de um acontecimento, a ocorrer em certo espaço definido para um certo público alvo, podendo dar-se de forma física ou virtual (MEIRELLES, 1999, p. 21). Nesse sentido, consiste em ferramenta de grande valia para o 
marketing, uma vez que esta possibilita o alcance do público desejado, divulgando o produto ou a marca, tornando-os mais conhecidos, o que aumenta a possibilidade de expansão de clientes e de mercado.

Um evento é composto, em regra, por quatro principais fases: (i) planejamento, sendo este o momento em que são estipuladas metas, objetivos, e a melhor forma de alcança-los; (ii) organização, que envolve o trabalho dos mais diversos profissionais, que devem atuar de forma conjunta e em sintonia, mas sempre respeitando as preferência do dono do evento; (iii) execução, que envolve o momento em que o planejamento e a organização são colocados em prática e (iv) pós-evento, que envolve o momento em que realiza-se o checklist e relatórios das atividades desenvolvidos no evento, agradecimento aos colaboradores, a desmontagem da parte física, edição do material audiovisual, prestação de contas, avaliação do evento para fins de aprimoração e divulgação de resultados. (WATT, 2006; MARTIN, 2009, p. 78).

Quanto ao número de participantes do público que estima-se que estejam presente, o evento pode ser classificado em (i) micro, que comporta cerca de cem participantes; (ii) pequeno, quando estima a presença de cem a quinhentos participantes; (iii) médio, quando envolve um número máximo de dois mil participantes; (iv) grande porte, que em regra é realizado por empresas, podendo ter de dois mil e quinhentos a cinco mil participantes (MARTINS, 2003, p. 23-40). Ainda pode ser classificado em relação a constância, podendo ser: fixo, móvel ou esporádico.

Quanto ao perfil dos participantes, este é baseado no público alvo do evento, sendo dividido em três categorias básicas, sendo elas (i) a geral, em que os participantes podem ser de diversos setores; (ii) o dirigido, direcionado a grupos que possuem interesses em comum, e (iii) específico, composto por profissionais e técnicos detentores de interesses em comum. O perfil também deve levar em consideração a área de interesse do público, que pode ser artística, científica, cultural, desportiva, de lazer, de divulgação, religiosa, dentre outros.

Nesse sentido, as peculiaridades do perfil do público a ser atingido, as características e os objetivos do evento e sua tipologia, são importantes para verificar se a melhor forma de o executar com base no tipo de adesão, podendo ser um evento aberto ou fechado: 
Tabela 1: Classificação de Eventos em relação ao público.

\begin{tabular}{l|l}
\hline \multicolumn{1}{c|}{ Eventos Abertos } & \multicolumn{1}{c}{ Eventos Fechados } \\
\hline São os Eventos que podem ser divididos por & $\begin{array}{l}\text { Possui um público selecionado } \\
\text { em que cada participante recebe }\end{array}$ \\
dois tipos de adesão, o que pode ser & convite específico e restritivo de \\
apresentado a um determinado tipo de & quem organiza e que \\
público, podendo ser aderido através de & normalmente paga todas as \\
inscrições gratuitas ou taxas; e evento com & despesas do evento, por \\
acesso livre, sem taxas ou restrições, & \\
atingindo um público em geral como por & \\
exemplo, shows de músicas ao vivo & \\
organizados por órgãos públicos. &
\end{tabular}

Fonte: Elaborada autora a partir de Matias (2010, p. 106)

Em relação a tipologia, com base nas peculiaridades e características do evento, esse pode ser um congresso, colóquio, simpósio, conclave, competição, coquetel, entrevista, feira, exposição, festival, festa, Brainstorming, Brunch, Coffe Break, palestra, workshop, oficina, show, dentre outros.

Para a organização de um evento, é necessário a presença de diversos de profissionais dos mais diferentes ramos e habilidades, sendo importante que todos trabalhem de forma conjunta e em sintonia. Ademais, a previsão de recursos financeiros e materiais deve estar predefinida para fins de evitar possíveis restrições ou repercussões negativas durante a organização do evento. Dentre os recursos materiais mais utilizados, destacam-se os seguintes: 
Tabela 2: Recursos Materiais para a Realização de Eventos.

\begin{tabular}{|c|c|}
\hline Ambientação & $\begin{array}{l}\text { Climatização, iluminação, arranjos ornamentais, painéis com logotipo, } \\
\text { nome do evento e dos patrocinadores, toalhas, tapetes, cenários, mastro. }\end{array}$ \\
\hline Apoio & Máquina fotográfica, filmadora. \\
\hline Banheiros e Copa & Papel higiênico, papel toalha, guardanapos, água, copos, xícaras. \\
\hline Elétrica & Gerador, adaptadores para tomadas. \\
\hline Hospedagem & Escolha de hotéis, reserva antecipada, confirmação de reserva. \\
\hline Identificação & Lista de convidados, crachás. \\
\hline $\begin{array}{l}\text { Montagem e } \\
\text { Instalação }\end{array}$ & $\begin{array}{l}\text { De balcão ou box de informações, e todas as dependências que serão } \\
\text { utilizadas para o evento como sala de imprensa, segurança, limpeza, } \\
\text { serviços de copa, serviços médicos, área social para descanso, coffe } \\
\text { break, e outros. }\end{array}$ \\
\hline $\begin{array}{l}\text { Recursos } \\
\text { Audiovisuais }\end{array}$ & $\begin{array}{l}\text { Equipamentos de áudio (microfones de lapela, auriculares, com ou sem } \\
\text { fio, pedestal, amplificador, música ambiente, etc.), equipamentos de } \\
\text { projeção de imagens (TV, telão, projetor, etc.). }\end{array}$ \\
\hline $\begin{array}{l}\text { Recursos } \\
\text { Materiais }\end{array}$ & $\begin{array}{l}\text { Balcão de apoio, material de papelaria (papel, envelope, caneta, lápis), } \\
\text { material de participantes (pasta, brindes, crachá, ticket de refeição), } \\
\text { equipamentos (telefones, fax, computadores, impressoras, calculadora). }\end{array}$ \\
\hline $\begin{array}{l}\text { Segurança e } \\
\text { Vigilância }\end{array}$ & $\begin{array}{l}\text { Contratação de pessoal treinado, de empresa, uniforme e equipamentos, } \\
\text { treinamento de acordo com o tipo de evento. }\end{array}$ \\
\hline $\begin{array}{l}\text { Serviço de } \\
\text { Transporte e } \\
\text { Circulação } \\
\text { Interna. }\end{array}$ & $\begin{array}{l}\text { Transportes aéreos, terrestres e hidroviários, tendo alguns beneficios } \\
\text { adquiridos como tarifas com descontos especiais para participantes, } \\
\text { passagem de cortesia. }\end{array}$ \\
\hline
\end{tabular}

Elaborada a partir do Manual de Organização de Eventos do Senado Federal (2013, p. 37) e Matias (2010, p. 150-161).

Sendo assim, nota-se que para o efetivo acontecimento de um evento, é preciso um planejamento prévio, detalhado e bem elaborado, com base nas características do produto ou marca a ser divulgado, nos objetivos a serem alcançados e no público alvo a ser atingido ao final. Somado a isso, deve-se formar uma equipe de profissionais, tanto responsáveis pelo planejamento quanto pela execução, que sejam devidamente qualificados e aptos a trabalhar em equipe, para que sejam possíveis a realização, sucesso e os bons resultado como retorno.

\section{Eventos gastronômicos como estratégia eficaz de marketing}

Estratégia de marketing pode ser definida como plano de ação com a finalidade de direcionar as operações de uma empresa, com a estipulação de um conjunto de ações que devem ser utilizadas com vistas ao crescimento do negócio, a atração e manutenção de clientes; a vitória no meio competitivo; o desenvolvimento administrativo, estrutural e financeiro da 
empresa; e o crescimento de mercado (THOMPSON JR; STRICKLAND III; GAMBLE, 2011, p. 4).

Logo, essa ferramenta é utilizada como método de atrair e agregar valor para a empresa, mostrando para os clientes a vantagem e o diferencial da empresa em comparação com as demais. Assim, um marketing bem elaborado pode causar efeitos positivos no público alvo e trazer um grande retorno para a empresa. Para ter bons resultados, a estratégia utilizada não precisa ser grandiosa e cara, podendo ser simples, sutil e com menor orçamento, e mesmo assim atingir os objetivos com sucesso. Nesse sentido, Braga (2012, p. 173) afirma que um bom planejamento de marketing bem feito é capaz de propiciar bons resultados e maior visibilidade no mercado.

Dentre as várias estratégias, destacam-se as competitivas genéricas, as de crescimento e as de comunicação. As primeiras são utilizadas por empresas que buscam métodos para ganhar uma vantagem sustentável no mercado (CAMPOS, 2009, p. 35), a segunda ocorre quando a empresa deseja aumento de vendas, maior participação no mercado e aumento no valor da empresa, podendo ocorrer de forma vertical ou horizontal; e a terceira tem o objetivo de estabelecer um plano comunicacional entre a empresa e os clientes, para influencia-los, bem como para saber de suas opiniões, permitindo que, ao final a análise dos dados colabore para o crescimento da empresa.

As estratégias competitivas genéricas se dividem em de custo ou de foco. As genéricas dividem-se em competitiva de custo, onde a empresa visa o aumento da produção e redução de gastos, para fins de proporcionar o menor preço possível para o consumidor; e a de foco, cuja finalidade é a empresa se especializar no atendimento a segmento específico do mercado, com base na diferenciação ou no custo.

Em relação as estratégias de crescimento, a empresa precisa investir em inovação e outras formas de agregar valor ao produto ou serviço que vende, mesmo se esse produto ou serviço ainda não tenha apresentado bons resultados (EDMUNDO, 2013, p. 26). Por seu turno, as estratégias de comunicação são guiadas por práticas utilizadas para chegar aos clientes, uma delas é o marketing direto, que pode ser realizado por envio de mensagens por e-mail, divulgações por folhetos, promoções, sítios eletrônicos, perfil em alguma rede social, eventos, dentre outros. 
A comunicação é importante para o marketing empresarial, devendo envolver os fatores internos e externos da empresa, uma vez que a interação entre todos os envolvidos é uma forma de se facilitar o alcance dos resultados esperados (ARRUDA,2011). Assim ocupa o centro da atividade sistêmica, sendo importante para a criação e manutenção da imagem positiva do negócio. (BRITO; FONTES, 2002). Ademais, deve-se buscar manter a comunicação durante todo o processo, isto porque além de ser veículo de recepção e trocar informações, tem a capacidade de ocasionar um "boca a boca" favorável (COSTA ET AL., 2004).

Dentre os métodos de comunicação de marketing, os eventos têm sido considerados fortes divulgadores e formadores de networking (MONDO; COSTA, 2010), motivo pelo qual a gastronomia tem utilizado dos eventos como forma útil e eficaz de divulgação de suas propostas e seus pratos; podendo ser festivais de bebidas, gêneros de alimentos ou pratos regionais.

No caso do evento gastronômico, este deve ser momento em que a função interativa do marketing seja supervalorizada, uma vez que o público está experimentando o produto ou serviço naquele mesmo momento, sendo capaz de divulgar em tempo real sua experiência nas redes sociais, que é uma forma de boca a boca.

Os eventos são entendidos como uma ferramenta de marketing de comunicação, pois envolve uma interrelação estratégica entre vários canais e diversas possibilidades, sendo ação concreta passível de resultados positivos permanentes. (BRITO; FONTES, 2002). Nesse sentido, são classificados como veículos de comunicação dirigida, aproximativa e interativa (BRITTO; FONTES, 2002); em razão disso, é estratégia capaz de atingir o público almejado, bem como de oportunizar a aproximação de produtos e serviços, por meio de uma interação entre eles.

Nesse contexto, os eventos gastronômicos são realizados com base, em regra, com uso de determinado produto, ingrediente específico, ou tipo de comida; como, a título de exemplo o Festival Comida Di Buteco, que se baseia em uma disputa de petiscos; Festival Ver-o-Peso, busca difundir a culinária e ingredientes locais do Belém/PA; Festa da Colônia, Gramado e Canela; envolvendo a culinária das regiões e de origem alemã, português e italiana; e o Restaurante Week, estimula que os restaurantes participantes reinventem pratos típicos do local.

Esses eventos resultam em grande volume de movimentação do mercado local, crescimento econômico, geração de empregos, turismo, troca de conhecimentos, e o mais 
importante que é a divulgação do restaurante, bistrô, foodtruck dentre outros; gerando uma associação do tipo de comida, tempero, prato etc.; àquele determinado estabelecimento alimentício.

Diretamente relacionados as estratégias de marketing utilizadas no setor gastronômico, cabe comentar acerca do marketing sensorial, relacionados aos sentidos do cliente; e o experimental; visa atrair o consumidor em razão da experiência marcante que obteve naquele lugar ou com aquele produto.

Quando ao marketing sensorial, tem como objetivo estimular a pessoa a associar um sentimento aquela marca ou produto, por meio do estímulo de seus sentidos, uma vez que esses estímulos são capazes de despertar sentimentos e mexer com a mente (SCHMITT, 2000, p. 41). Busca despertar certos sentidos e diferentes percepções no individuo, onde ele irá interpretar o ambiente e o prato que lhe é apresentado, dando um significado para este (PRIDE; FERREL, 2000, p. 155). Assim, o cheiro agradável do local e da comida servida, o apego ao gosto específico de certo prato, pode estar correlacionado a sentimentos e emoções vivenciadas em determinado estabelecimento que foram gerados pelo marketing sensorial.

Por sua vez, o marketing experimental visa apresentar produtos, campanhas e estruturas que mexam com as emoções e com a cabeça dos clientes, por meio de uma experiência que marquem a vida destes. Deve ser algo inovador, isto porque as pessoas já estão acostumadas com a maioria das características e benefícios oferecidos pelas marcas e produtos, assim, aquele estabelecimento que for capaz de oportunizar uma nova experiência, tem mais chances de obter sucesso no mercado (SCHMITT, 2000).

Com base nisso, os eventos gastronômicos devem ser utilizados como uma oportunidade de apresentar um local que produza um efeito emocional específico, criar experiências inovadoras e interessantes, capazes de mexer com os sentidos, criar momentos relevantes e despertar o interesse do cliente em retornar em razão disso. Logo, possuir um ambiente capaz de proporcionar essa nova experiência, tanto emocional quanto comportamental, consiste em aumentar as chances de se criar um elo entre o restaurante e o cliente.

Por fim, cabe mencionar o marketing referencial, é considerado a forma de marketing que mais traz resultado para a empresa; e consiste no resultado do momento vivenciado pelo cliente no restaurante ou pela comida apresentada. Assim, a experiência agradável é o que o 
motivará a divulgar a empresa para outras pessoas, sendo uma parte essencial das estratégias de marketing.

Sendo assim, os eventos revelam ser ótima estratégia de comunicação e atração de clientes, que tem se revelado eficaz na captação de clientes. Pela ótica do marketing é uma forma de conquistar novos cliente, assim como de manter os antigos, por meio do uso de uma relação direta e mais íntima com o público, configurando método de amadurecimento público e combate da concorrência.

\section{Considerações Finais}

Um evento bem-sucedido vira notícia. Com base nisso, deve-se investir nesse tipo de marketing como forma de ferramenta de atração, retenção e manutenção de consumidores, sendo necessário, que o evento seja realizado da melhor forma possível, atento ao dia que será realizado, a estimativa de participantes presentes, a escolha de local adequado e de fácil acesso, e, principalmente, a apresentação de uma boa comida e bebidas, recepção ímpar e bem planejada, para que seja possível alcançar o objetivo de divulgação dos produtos ou serviços e estabelecimento da lealdade dos clientes.

É incontroverso que a gastronomia é de interesse geral, e, se acompanhada de um bom planejamento e execução, é possível de se tornar algo significativo para os clientes, criando, conforme comentado, não apenas a ideia de local de alimentação, mas uma associação sensorial, sentimental e referencial, configurando local significativo e que cria um desejo de retorno frequente.

Nesse cenário o marketing se apresenta como ferramenta importante na elaboração de estratégias de alcance de consumidores, e os eventos gastronômicos, por sua vez, como método eficaz de divulgação dos pratos e de criação de laços entre o consumidor e a proposta do restaurante.

512 Id on Line Rev. Mult. Psic. V.12, N. 42, p. 501-514, 2018 - ISSN 1981-1179 Edição eletrônica em http://idonline.emnuvens.com.br/id 


\section{Referências}

ARRUDA, Nirlene Aparecida. importância da comunicação estratégica empresarial. Rev. Eccom, V. 2 (3), 2011. Disponível em: < http://publicacoes.fatea.br/index.php/eccom/article/view/421/274>. Acesso em: 28/09/2018.

BRAGA, Roberto M.M. Gestão da Gastronomia. $3^{\text {a }}$ ed. São Paulo: Editora Senac, 2012.

BRITTO, Janaina; FONTES, Nena. Estratégias para eventos: uma ótica do marketing e do turismo. São Paulo: Aleph. 2002.

CALINO, Carolinne Fortini Dias Rodrigues; COUTINHO, Rhanica Evelise Toledo; BIZERRA, Carine Camara; GARCIA, Sônia Cardoso Moreira; SÁ, Marco Aurélio Lima de. O Evento como Ferramenta de Atração e Retenção de Clientes no Setor Gastronômico. 2014. Disponível em: < https://www.aedb.br/seget/arquivos/artigos14/1620418.pdf > . Acesso em: 28/09/2018.

CAMPOS, Wagner. O que é Estratégia Competitiva? 2009. Disponível em: < http://www.administradores.com.br/artigos/marketing/o-que-e-a-estrategia-competitiva/28236/> .

Acesso em: 28/09/2018.

COELHO, Diogo. Eventos: conceitos, classificação e tipologia. Disponível em: < https://slideplayer.com.br/slide/3683156/ >. Acesso em: 28/09/2018.

COSTA, Benny Kramer; MARINHO, Luciana Freire de Lima Marinho; ALMEIDA, Célio Mauro Placer de Almeida. Marketing de relacionamento: Uma Estratégia para a Indústria Hoteleira na Captação e Realização de Eventos. In: Anais...VII Semead - Seminários em Administração, São Paulo, 2004.

DAMATTA, Roberto. O que é o Brasil. 1ª Edição, Rio de Janeiro(RJ): Rocco, 2004.

EDMUNDO, Yuri. Estratégias de Crescimento da Empresa. 2013. Disponível em: < https://www.administradores.com.br/artigos/negocios/estrategias-de-crescimento-da-empresa/70596/> . Acesso em: 28/09/2018.

ENGEL, James. F; BLACKWELL, Roger.D; MINIARD,Paul.W. Comportamento do consumidor. 9. ed. Rio de Janeiro: Pioneira Thompson Learning, 2005.

FÉLIX, Joana D’Arc Bicalho, ARGOLO, Gisele Dias. Marketing na atmosfera gourmet: estratégias das empresas e atributos valorizados por clientes. Monografia (Graduação), Brasília, Centro Universitário de Brasília - UniCEUB Faculdade de Tecnologia e Ciências Sociais Aplicadas - FATECS, 2015.

FRANCO, Ariovaldo. De caçador a Gourmet, p. uma história da gastronomia. São Paulo, p. Editora Senac São Paulo, $4^{\mathrm{a}}$ ed. rev., 2006.

GRONROSS, Christian. Marketing: gerenciamento e serviços. Rio de Janeiro: Campus, 1993.

GUMMESSON, Evert. Marketing de relacionamento total: gerenciamento de marketing, estratégia de relacionamento, abordagens de CRM para economias de rede. Porto Alegre: Bookman, 2005. 
KOTLER, Philip; ARMSTRONG, Gary. Princípios do Marketing. São Paulo: Prentice Hall, 2003. KOTLER, Philip ; KELLER, Kevin Lane. Administração de Marketing. 12a ed. São Paulo, Pearson Prentice Hall, 2006.

LOVELOCK, Christopher; WRIGHT, Lauren. Serviços: marketing e gestão. São Paulo: Saraiva., 2003.

MATIAS, Marlene. Organização de Eventos, p. Procedimentos e Técnicas. São Paulo, p. Manole, $5^{\text {a }}$ Edição, 2010.

MARTINS, Vanessa. Manual Prático de Eventos. São Paulo, p. Atlas, 2003.

MEIRELLES, Gilda Fleury.Tudo sobre eventos. São Paulo: STS, 1999.

MELLO, Eliane Fissicaro. Antecedentes da lealdade dos consumidores de telefonia celular póspago. 2008. 139 f. Dissertação de mestrado em Administração - Universidade FUMEC, Belo Horizonte, 2008.

PRIDE, William M; FERREL, O.C. Marketing: conceitos e estratégias. Rio de Janeiro: LTC, 2000.

SANTOS, Beatriz; MORSCH, Marco Aurélio. Comportamento do Consumidor: conceitos e casos. São Paulo: Editora Prentice Hall, 2005.

SCHIMITT, Bernd. Marketing Experimental: Sua Empresa e suas marcas conquistando o sentir e o pensar, o agir e o identificar-se dos clientes. 1.ed. Nobel, 2000.

THOMPSON JR. Arthur A., STRICKLAND III A.J., GAMBLE John E.; tradução Roberto Glaman, Kátia Aparecida Roque; revisão técnica Charles Kirschbaum, Tatiana Iwai. Administração Estratégica. Porto Alegre, p. 15ª Edição, 2011.

TERRY, G. Marketing de Relacionamento. São Paulo: Editora Atlas S.A, 1993.

WATT, David. Gestão de Eventos em Lazer e Turismo. São Paulo, p. Editora Bookman, 2006.

\section{Como citar este artigo (Formato ABNT):}

SANT'ANNA, André Luís; SILVA, Daniele Bastos da. Eventos gastronômicos: a nova estratégia de marketing e divulgação utilizada pelos restaurantes. Id on Line Rev.Mult. Psic., 2018, vol.12, n.42, p. 501-514. ISSN: 1981-1179.

Recebido: 19/09/2018;

Aceito: $29 / 09 / 2018$ 